\title{
BMJ Open Evaluation of postextraction bleeding incidence to compare patients receiving and not receiving warfarin therapy: a cross-sectional, multicentre, observational study
}

\author{
Hiroshi Iwabuchi, ${ }^{1}$ Yutaka Imai, ${ }^{2}$ Soichiro Asanami, ${ }^{3}$ Masayori Shirakawa, ${ }^{4}$ \\ Gen-yuki Yamane, ${ }^{5}$ Hideki Ogiuchi, ${ }^{6}$ Kenji Kurashina, ${ }^{7}$ Masaru Miyata, ${ }^{8}$ \\ Hiroyuki Nakao, ${ }^{9}$ Hirohisa Imai ${ }^{9}$
}

To cite: Iwabuchi $\mathrm{H}$, Imai Y, Asanami S, et al. Evaluation of postextraction bleeding incidence to compare patients receiving and not receiving warfarin therapy: a cross-sectional, multicentre, observational study. BMJ Open 2014;4:e005777. doi:10.1136/bmjopen-2014005777

- Prepublication history for this paper is available online. To view these files please visit the journal online (http://dx.doi.org/10.1136/ bmjopen-2014-005777).

Received 24 May 2014 Revised 1 October 2014 Accepted 6 October 2014

CrossMark

For numbered affiliations see end of article.

Correspondence to Dr Hiroshi Iwabuchi; iwabuchi@kdu.ac.jp

\section{ABSTRACT}

Objectives: We investigated incidence and risk factors for postextraction bleeding in patients receiving warfarin and those not receiving anticoagulation therapy.

Design: Cross-sectional, multicentre, observational study.

Setting: 26 hospitals where an oral surgeon is available.

Participants: Data on 2817 teeth (from 496 patients receiving warfarin, 2321 patients not receiving warfarin; mean age (SD): 62.2 (17.6)) extracted between 1 November 2008 and 31 March 2010, were collected. Warfarin-receiving patients were eligible when prothrombin time-international normalised ratio (PT-INR) measured within 7 days prior to the extraction was less than 3.0.

Interventions: Simple dental extraction was performed, and incidence of postextraction bleeding and comorbidities were recorded.

Primary and secondary outcome measures:

Postextraction bleeding not controlled by basic haemostasis procedure was clinically significant.

Results: Bleeding events were reported for $35(7.1 \%)$ and $49(2.1 \%)$ teeth, of which $18(3.6 \%)$ and $9(0.4 \%)$ teeth were considered clinically significant, in warfarin and non-warfarin groups, respectively, the difference between which was $3.24 \%(\mathrm{Cl} 1.58 \%$ to $4.90 \%)$. The incidence rates by patients were $2.77 \%$ and $0.39 \%$, in warfarin and non-warfarin groups, respectively (incidence difference $2.38 \%$, Cl $0.65 \%$ to $4 / 10 \%$ ). Univariate analyses showed that age (OR 0.197 , $\mathrm{p}=0.001$ ), PT-INR (OR 3.635, $\mathrm{p}=0.003$ ), mandibular foramen conduction anaesthesia (OR 4.854, $p=0.050$ ) and formation of abnormal granulation tissue in extraction socket (OR 2.900, $\mathrm{p}=0.031$ ) significantly correlate with bleeding incidence. Multivariate analysis revealed that age (OR $0.126, p=0.001)$, antiplatelet drugs (OR 0.100, $\mathrm{p}=0.049$ ), PT-INR (OR 7.797, $\mathrm{p}=0.001)$ and history of acute inflammation at extraction site (OR 3.722, $p=0.037$ ) were significant risk factors for postextraction bleeding.
Strengths and limitations of this study

- The present study examined the difference between the incidence of postextraction bleeding in patients receiving and not-receiving warfarin, which few previous studies to date have reported.

- The study included dental facilities where at least one or more certified oral surgeons are available in order to standardise skills of the operators and capability of the facilities for providing advanced care in the event of significant bleeding.

- We also analysed the risk factors for postextraction bleeding events in patients receiving warfarin.

- Owing to the study design, we may have underestimated the incidence of postextraction bleeding that may occur in community dental clinics.

- Although we tried to standardise the dental extraction procedure, there might have been interfacility differences.

Conclusions: Our results suggest that there is slight but significant increase in the incidences of postextraction bleeding in patients receiving warfarin. Although absolute incidence was low in both groups, the bleeding risk is not negligible.

\section{INTRODUCTION}

Until recently, the common procedure for tooth extraction in patients continuously receiving warfarin (WF) or other antiplatelet therapy was to discontinue or reduce the dose to minimise the risks of odontorrhagia. However, the procedure has been re-evaluated since cases of thromboembolic complications after dental extraction with WF cessation were reported. $^{1-3}$ Thereafter, many studies, including randomised trials, ${ }^{4-6}$ cohort studies $^{7-9}$ and 
meta-analyses, ${ }^{10-12}$ have been conducted, all of which reported no significant differences in incidence of postextraction bleeding and/or other haemorrhagic complications, concluding that in patients whose prothrombin time-international normalised ratio (PT-INR) is within desirable therapeutic range, dental extraction can be performed safely without cessation of WF. Clinical guidelines published after these studies advised that patients whose PT-INR values were within the recommended therapeutic ranges should continue $\mathrm{WF}$ when undergoing dental extraction. ${ }^{13-15}$ However, there have been few studies that specifically addressed a difference in the bleeding incidences and its $95 \%$ CI comparing tooth extraction cases in patients receiving and not receiving WF.

Given these circumstances, we evaluated the difference in postextraction bleeding incidences in otherwise healthy controls without WF administration (non-WF group) and in patients under reasonable coagulation control with WF (WF group). We selected the participants for the latter group whose PT-INR was 3.0 or lower at the time of the procedure, as the PT-INR of 3.0 was indicated as the maximum safety threshold for tooth extraction in the Guidelines for Patients on Antithrombotic Therapy Requiring Dental Extraction in Japanese. ${ }^{16}$ We also investigated the risk factors for the incidence of postextraction bleeding in patients receiving WF therapy.

\section{MATERIALS AND METHODS}

This was a prospective multicentre observational study of postextraction bleeding events in patients receiving and not receiving WF therapy.

\section{Study period and eligibility criteria}

Twenty-six hospitals located across Japan participated. This study included patients who underwent simple tooth extraction from 1 November 2008 to 31 March 2010 at the department of oral surgery of these hospitals and who met the eligibility criteria listed below. Simple tooth extraction referred to a tooth removed without traumatising the surrounding alveolar bone or elevating a mucoperiosteal flap.

Eligibility criteria included the following: 20 or more years of age at the time of tooth extraction; no contraindications for tooth extraction; surgery was performed by oral surgeon with a minimum of 3 years of experience in dental practice; the oral extraction procedure lasted for no longer than $15 \mathrm{~min}$; and platelet count within 7 days prior to the procedure was normal. In addition, in patients receiving WF therapy, PT-INR measured within 7 days prior to the procedure should be less than 3.0. Patients receiving antiplatelet medication were not excluded but recorded as such. According to "The Guidelines for Patients on Antithrombotic Therapy Requiring Dental Extraction", ${ }^{14}$ we instructed the participating hospitals that dental extraction should be performed without discontinuing or reducing the dose of
$\mathrm{WF}$ in patients whose PT-INR was not exceeding 3.0 when measured within 7 days prior to the procedure.

\section{Study variables}

The variables analysed in this study were: bleeding events, patient's age and sex, position of the removed tooth, instruments used for removal (forceps only, elevators only, forceps and elevators), reasons for extraction, use of antiplatelet drugs, PT-INR values measured within 7 days before exodontia (only for patients receiving chronic WF therapy), comorbidities possibly influencing haemostasis, use of vasoconstrictors, combined use of local anaesthetics and vasoconstrictors, use of inferior alveolar nerve block, severity of gingivitis after extraction (none, mild, moderate, severe), formation of abnormal granulation tissue in the extraction socket (none, little, medium, much), history of acute inflammation at extraction site and postextraction infection.

\section{Haemostasis}

The haemostatic methods for patients not receiving WF were chosen at the discretion of the dentist or oral surgeon performing the procedure. In patients on WF therapy, either absorbable oxidised cellulose or gelatin sponge was implanted into the alveolar socket, and wound margins were sutured. In both groups of patients, topical haemostatic agents other than epinephrine, systemic haemostatic agents and splints were prohibited until primary haemostasis was observed. In patients who had multiple teeth extracted in one session, possible postextraction bleeding was examined for each tooth. In a patient receiving $\mathrm{WF}$, the postextraction procedure defined above was performed each time after a tooth was removed.

\section{Permitted drugs}

Use of local anaesthetics containing vasoconstrictors (eg, epinephrine and felypressin) was allowed at doses commonly given. In WF-treated patients, penicillins or cefems (eg, cefcapene pivoxil and cefditoren pivoxil) were the primary choice of prophylactic antibiotics for their minimal interaction with WF. For those who were allergic to penicillins, clarithromycin was recommended. Use of analgaesics, such as acetaminophen, nonsteroidal anti-inflammatory drugs and cyclo-oxygenase-2 inhibitors was allowed at ordinary doses.

\section{Confirmation of haemostasis}

All patients were asked to bite down on a roll of gauze for a maximum of $30 \mathrm{~min}$ for astriction of the wound. After release of the biting pressure, the wound was examined for haemostasis. Patients visited the hospital on the next day of surgery to check for possible bleeding, and were instructed to present at the hospital for treatment, if bleeding should occur later. The follow-up period was 7 days postoperatively. 


\section{Follow-up of bleeding events}

If a patient had a bleeding event during the follow-up period, the severity of the haemorrhage and blood pressure were recorded. If the patient was on WF therapy, his or her PR-INR values were measured in addition.

\section{Evaluation of bleeding events}

In this study, bleeding events occurring in the follow-up period were classified into one of the following 5 grades: 0 , no bleeding; 1, excessive blood clotting in the socket, no treatment required; 2-1, haemostasis achieved by compressing the wound longer than $30 \mathrm{~min}$; 2-2, oozing haemorrhage observed on or after the next day of the procedure, in which haemostasis was achieved by simple compression; 3, bleeding required treatments other than wound compression, such as application of compression brace and/or coagulation by electrotome was needed. Events of grade 2-2 and higher were regarded as clinically significant, and were defined as postextraction bleeds in this study.

\section{Statistical analysis}

Data were collected by a tooth, but not by a patient. This means that patients who had multiple teeth extraction were counted multiple times for the number of extracted teeth. Data were then sorted and analysed by the anatomical positions. The difference in postextraction bleeding incidence between patients receiving and not receiving WF therapy and its 95\% CI were calculated. In addition, a multivariate logistic regression analysis was conducted to identify risk factors for postextraction bleeding in WF-treated patients. Adjusted ORs, their 95\% CI and $\mathrm{p}$ values were calculated controlling for major confounders. Explanatory variables with a significance level of $\mathrm{p}<0.20$ on univariate analyses were included in the multivariate logistic regression model. Statistical analyses were performed using SPSS software (V.15.0, SPSS Japan Inc, Tokyo, Japan).

\section{Ethics}

The objective of this study was explained in detail to potential study participants so that they could make an informed decision. Informed consent was obtained orally or by a written document, according to the recommendation of the ethics committee of each participating facility. Patients' personal information was stored in a de-identified but linkable format during the 7-day follow-up period and was rendered completely anonymous thereafter. This study was reviewed and approved by the ethics committee of the National Hospital Organization Tochigi Medical Center, Tochigi, Japan, prior to its conduct. The approved protocol was distributed to the participating hospitals to keep the uniformity of the study.

\section{RESULTS}

Totally, 3515 case reports were submitted from the participating investigators. Of these, 698 cases were eliminated because of protocol deviations and/or insufficient data documentation, leaving 2817 for further analysis.

\section{Postextraction bleeding incidence}

Bleeding events including minor haemorrhagic episodes were reported for 35 of 496 teeth $(7.1 \%)$ of the WF group and for 49 of 2321 teeth $(2.1 \%)$ of the non-WF group, with a total of 84 teeth. Clinically significant postextraction bleeds (ie, grade 2-2 or higher) were reported for 27 teeth, including $18(3.6 \%)$ and $9(0.4 \%)$ from the WF and non-WF groups, respectively (table 1 ).

\section{Breakdown of removed teeth by sex and study group}

The mean (SD) age of all study participants was 62.2 (17.6) years, and 1446 and 1371 teeth were removed from males $(51.3 \%)$ and females $(48.7 \%)$, respectively. The WF group had a mean (SD) age of 70.3 (10.9) years, and reported removal of 496 teeth, 320 from males $(64.5 \%)$ and 176 from females $(35.5 \%)$. The non-WF group had a mean (SD) age of 60.4 (18.3) years, and reported removal of 2321 teeth, 1126 from males $(48.5 \%)$ and 1195 from females $(51.5 \%$; table 1$)$.

The difference in postextraction bleeding incidence between the WF group and non-WF group was $3.24 \%$ and its $95 \%$ CI was $1.58 \%$ to $4.90 \%$. On patient analysis, clinically significant bleeding occurred in a total of 361 of 2146 patients $(2.77 \%$ and $0.39 \%$, in WF and non-WF group, respectively), the incidence difference between which was $2.38 \%$ (95\% CI $0.65 \%$ to $4.10 \%$; table 2 ).

\section{Risk factors for postextraction bleeding in WF-treated patients}

Univariate analyses showed that age (OR 0.197, $\mathrm{p}=0.001$ ), PT-INR (OR 3.635, $\mathrm{p}=0.003$ ), inferior alveolar nerve block (OR 4.854, $\mathrm{p}=0.050$ ) and formation of abnormal granulation tissue in extraction socket (OR $2.900, \mathrm{p}=0.031$ ) were significantly correlated with postextraction bleeding (table 3). In addition to these variables, position of the removed tooth, reasons for extraction, antiplatelet drugs, comorbidities possibly influencing haemostasis and history of acute inflammation at extraction site were found to have $p$ values lower than 0.2 by univariate analysis. Consequently, these parameters were included as explanatory variables in the multivariate regression analysis. The results showed that age (OR 0.126, $\mathrm{p}=0.001)$, antiplatelet drugs (OR 0.100, $\mathrm{p}=0.049)$, PT-INR (OR 7.797, $\mathrm{p}=0.001)$ and history of acute inflammation at extraction site (OR 3.722, $\mathrm{p}=0.037$ ) were significant risk factors for postextraction bleeding (table 4).

\section{DISCUSSION}

In WF-treated patients, thromboembolic events were reported in varying frequency in the literature, ranging as low as $0.059 \%^{17} 18$ to as high as $1 \%^{1}$ when WF was discontinued prior to dental extraction, while few reported serious postextraction bleeding associated with dental 
Table 1 Breakdown of extracted teeth by important classification variables

\begin{tabular}{|c|c|c|c|c|}
\hline Number of teeth by & $\begin{array}{l}\text { WF } \\
n=496\end{array}$ & $\begin{array}{l}\text { No WF } \\
n=2321\end{array}$ & $\begin{array}{l}\text { Total } \\
\mathrm{N}=2817\end{array}$ & p Value \\
\hline \multicolumn{5}{|l|}{ Age (years) } \\
\hline$<65$ & $124(25.0)$ & $1131(48.7)$ & $1255(44.6)$ & \multirow[t]{2}{*}{$<0.0001$} \\
\hline$\geq 65$ & $372(75.0)$ & $1190(51.3)$ & $1562(55.4)$ & \\
\hline \multicolumn{5}{|l|}{ Sex } \\
\hline Male & $320(64.5)$ & $1126(48.5)$ & $1446(51.3)$ & \multirow[t]{2}{*}{$<0.0001$} \\
\hline Female & $176(35.5)$ & 1195 (51.5) & $1371(48.7)$ & \\
\hline \multicolumn{5}{|l|}{ Type } \\
\hline Foretooth & 132 (26.6) & $663(28.6)$ & $795(28.2)$ & \multirow[t]{3}{*}{0.550} \\
\hline Premolar & $127(25.6)$ & $552(23.8)$ & $679(24.1)$ & \\
\hline Molar & $237(47.8)$ & $1106(47.7)$ & $1343(47.7)$ & \\
\hline \multicolumn{5}{|l|}{ Instrument } \\
\hline Forceps only & $171(34.5)$ & $604(26.0)$ & 775 (27.5) & \multirow[t]{3}{*}{0.000} \\
\hline Elevators only & $226(45.6)$ & 919 (39.6) & $1145(40.6)$ & \\
\hline Forceps and elevators & 99 (20.0) & $798(34.4)$ & 897 (31.8) & \\
\hline \multicolumn{5}{|l|}{ Cause for extraction } \\
\hline Periodontitis & 160 (32.3) & $533(23.0)$ & $693(24.6)$ & \multirow[t]{5}{*}{$<0.0001$} \\
\hline Caries & 87 (17.5) & $477(20.6)$ & $564(20.0)$ & \\
\hline Apical periodontitis & $219(44.2)$ & 1002 (43.2) & $1221(46.6)$ & \\
\hline Wisdom tooth pericoronitis & $23(4.6)$ & $192(8.3)$ & $215(7.6)$ & \\
\hline Other & 7 (1.4) & $117(5.0)$ & $124(4.4)$ & \\
\hline \multicolumn{5}{|l|}{ Status of antiplatelet therapy } \\
\hline Yes & $122(24.6)$ & $433(18.7)$ & $555(19.7)$ & 0.003 \\
\hline \multicolumn{5}{|c|}{ Use of local anaesthetics containing vasoconstrictors } \\
\hline Yes & $491(99.0)$ & $2265(97.6)$ & $2756(97.8)$ & 0.105 \\
\hline \multicolumn{5}{|c|}{ Use of inferior alveolar nerve block } \\
\hline Yes & $14(2.8)$ & $82(3.5)$ & $96(3.4)$ & 0.429 \\
\hline \multicolumn{5}{|c|}{ Comorbidity possibly influencing haemostasis } \\
\hline Hypertension & $267(53.8)$ & $715(30.8)$ & $982(34.9)$ & \\
\hline Diabetes mellitus & 89 (17.9) & $267(11.5)$ & $356(12.6)$ & \\
\hline Chronic hepatitis & $21(4.2)$ & $110(4.7)$ & $131(4.7)$ & \\
\hline Other & $68(13.7)$ & $212(9.1)$ & $280(9.9)$ & \\
\hline Multiple disorders & $341(68.8)$ & $1039(44.8)$ & $1380(49.0)$ & $<0.0001$ \\
\hline \multicolumn{5}{|c|}{ History of acute inflammation at extraction site } \\
\hline Yes & $216(43.5)$ & $829(35.7)$ & $1045(37.1)$ & 0.001 \\
\hline \multicolumn{5}{|c|}{ Gingival inflammation at extraction site } \\
\hline None & $298(60.1)$ & $1266(54.5)$ & $1564(55.5)$ & \multirow[t]{4}{*}{0.000} \\
\hline Mild & 95 (19.2) & $264(11.4)$ & 359 (12.7) & \\
\hline Moderate & $13(2.6)$ & $38(1.6)$ & $51(1.8)$ & \\
\hline Severe & $90(18.1)$ & $753(32.4)$ & $843(29.9)$ & \\
\hline \multicolumn{5}{|c|}{ Abnormal granulation tissue in extraction socket } \\
\hline None & $87(17.5)$ & $818(35.2)$ & 905 (32.1) & \multirow[t]{4}{*}{0.003} \\
\hline Little & $230(46.4)$ & $917(39.5)$ & $1147(40.7)$ & \\
\hline Medium & $134(27.0)$ & 441 (19.0) & $575(20.4)$ & \\
\hline Much & $45(9.1)$ & $145(6.2)$ & $190(6.7)$ & \\
\hline \multicolumn{5}{|c|}{ Severity of postextraction bleeding } \\
\hline G1 & $9(1.8)$ & $29(1.2)$ & $38(1.3)$ & \\
\hline G2-1 & $8(1.6)$ & $11(0.5)$ & $19(0.7)$ & \\
\hline G2-2 & $1(0.2)$ & $8(0.3)$ & $9(0.3)$ & \\
\hline G3 & $17(3.4)$ & $1(0.04)$ & $18(0.6)$ & \\
\hline total & $35(7.1)$ & $49(2.1)$ & $84(3.0)$ & $<0.0001$ \\
\hline G2-2+G3 & $18(3.6)$ & $9(0.4)$ & $27(1.0)$ & $<0.0001$ \\
\hline PT-INR (mean \pm SD) & $1.90 \pm 0.49$ & & & \\
\hline
\end{tabular}

extraction. Based on those data, the literature now suggests that WF should not be discontinued when performing dental extraction in WF-treated patients, regardless of incidences of thromboembolic events associated with dental procedure. ${ }^{5} 19-21$ The majority of previous studies assessed the safety of dental procedures 
Table 2 Incidences of clinically significant postextraction bleeding and their difference in patients receiving and not receiving WF

\begin{tabular}{lllll}
\hline & $\begin{array}{l}\text { Postextraction bleeding } \\
\text { incidences (\%) }\end{array}$ & $\begin{array}{l}\text { Difference in postextraction } \\
\text { bleeding incidence (\%) }\end{array}$ & 95\% Cl \\
\hline Incidence over total & numbers of teeth extracted (\%) & & & Upper \\
WF & 3.63 & 3.24 & 1.58 & 4.90 \\
No WF & 0.39 & & & \\
Incidence over total numbers of study participants (\%) & & 0.65 & 4.10 \\
WF & 2.77 & 2.38 & & \\
No WF & 0.39 & &
\end{tabular}

Table 3 Univariate analysis of postextraction bleeding events by potential risk factors

\begin{tabular}{|c|c|c|c|c|c|}
\hline & \multirow{2}{*}{$\begin{array}{l}\text { Incidence of postextraction } \\
\text { bleeding (\%) }\end{array}$} & \multirow[b]{2}{*}{ OR } & \multicolumn{2}{|l|}{$95 \% \mathrm{Cl}$} & \multirow[b]{2}{*}{ p Value } \\
\hline & & & Lower & Upper & \\
\hline \multicolumn{6}{|l|}{ Age (years) } \\
\hline$<65$ & 8.9 & 1 (Ref) & & & \\
\hline$\geq 65$ & 1.9 & 0.197 & 0.075 & 0.520 & $0.001^{*}$ \\
\hline \multicolumn{6}{|l|}{ Sex } \\
\hline Male & 3.4 & 1 (Ref) & & & \\
\hline Female & 4.0 & 1.164 & 0.443 & 3.057 & 0.759 \\
\hline \multicolumn{6}{|l|}{ Type } \\
\hline Foretooth or premolar & 2.3 & 1 (Ref) & & & \\
\hline Molar & 5.1 & 2.2249 & 0.830 & 6.091 & 0.111 \\
\hline \multicolumn{6}{|l|}{ Instrument } \\
\hline Forceps only & 2.9 & 1 (Ref) & & & \\
\hline Elevators alone or with forceps & 4 & 1.383 & 0.485 & 3.947 & 0.544 \\
\hline \multicolumn{6}{|l|}{ Cause for extraction } \\
\hline Caries, apical periodontitis, or other & 2.6 & 1 (Ref) & & & \\
\hline Periodontitis or wisdom tooth pericoronitis & 5.5 & 2.204 & 0.854 & 5.688 & 0.102 \\
\hline \multicolumn{6}{|l|}{ Status of antiplatelet therapy } \\
\hline No & 4.5 & 1 (Ref) & & & \\
\hline Yes & 0.8 & 0.174 & 0.023 & 1.318 & 0.090 \\
\hline PT-INR & & 3.635 & 1.5640 & 8.448 & $0.003^{*}$ \\
\hline \multicolumn{6}{|l|}{ Use of vasoconstrictors } \\
\hline No & 4.1 & 1 (Ref) & & & \\
\hline Yes & 0 & & & & \\
\hline \multicolumn{6}{|c|}{ Use of local anaesthetics containing vasoconstrictors } \\
\hline No & 0 & 1 (Ref) & & & \\
\hline Yes & 3.7 & & & & \\
\hline \multicolumn{6}{|l|}{ Use of inferior alveolar nerve block } \\
\hline No & 3.3 & 1 (Ref) & & & \\
\hline Yes & 14.3 & 4.854 & 1.002 & 23.513 & $0.050^{*}$ \\
\hline \multicolumn{6}{|l|}{ Comorbidity possibly influencing haemostasis } \\
\hline No & 5.8 & 1 (Ref) & & & \\
\hline Yes & 2.6 & 0.440 & 0.171 & 1.131 & 0.088 \\
\hline \multicolumn{6}{|l|}{ History of acute inflammation at extraction site } \\
\hline No & 2.5 & 1 (Ref) & & & \\
\hline Yes & 5.1 & 2.093 & 0.7970 & 5.492 & 0.134 \\
\hline \multicolumn{6}{|l|}{ Gingival inflammation at extraction site } \\
\hline None-to-mild & 3.3 & 1 (Ref) & & & \\
\hline Moderate-to-severe & 4.9 & 1.491 & 0.519 & 4.283 & 0.458 \\
\hline \multicolumn{6}{|c|}{ Abnormal granulation tissue in extraction socket } \\
\hline None-to-little & 2.2 & 1 (Ref) & & & \\
\hline Medium-to-much & 6.1 & 2.900 & 1.1040 & 7.619 & $0.031^{*}$ \\
\hline
\end{tabular}


Table 4 Multivariate analysis of postextraction bleeding events by potential risk factors

\begin{tabular}{|c|c|c|c|c|}
\hline & \multirow[b]{2}{*}{ OR } & \multicolumn{2}{|l|}{$95 \% \mathrm{Cl}$} & \multirow[b]{2}{*}{ p Value } \\
\hline & & Lower & Upper & \\
\hline \multicolumn{5}{|l|}{ Age (years) } \\
\hline$<65$ & 1 (Ref) & & & \\
\hline$\geq 65$ & 0.126 & 0.035 & 0.448 & $0.001^{*}$ \\
\hline \multicolumn{5}{|l|}{ Type } \\
\hline Foretooth or premolar & 1 (Ref) & & & \\
\hline Molar & 0.953 & 0.288 & 3.151 & 0.937 \\
\hline \multicolumn{5}{|l|}{ Cause for extraction } \\
\hline Caries, apical periodontitis, or other & 1 (Ref) & & & \\
\hline Periodontitis or wisdom tooth pericoronitis & 2.301 & 0.742 & 7.142 & 0.149 \\
\hline \multicolumn{5}{|l|}{ Status of antiplatelet therapy } \\
\hline No & 1 (Ref) & & & \\
\hline Yes & 0.100 & 0.010 & 0.986 & $0.049^{*}$ \\
\hline PT-INR & 7.797 & 2.2930 & 26.510 & $0.001^{*}$ \\
\hline \multicolumn{5}{|l|}{ Use of inferior alveolar nerve block } \\
\hline No & 1 (Ref) & & & \\
\hline Yes & 2.437 & 0.336 & 17.659 & 0.378 \\
\hline \multicolumn{5}{|l|}{ Comorbidity possibly influencing haemostasis } \\
\hline No & 1 (Ref) & & & \\
\hline Yes & 0.503 & 0.157 & 1.612 & 0.247 \\
\hline \multicolumn{5}{|l|}{ History of acute inflammation at extraction site } \\
\hline No & 1 (Ref) & & & \\
\hline Yes & 3.722 & 1.0850 & 12.773 & $0.037^{*}$ \\
\hline \multicolumn{5}{|l|}{ Abnormal granulation tissue in extraction socket } \\
\hline None-to-little & 1 (Ref) & & & \\
\hline Medium-to-much & 2.895 & 0.8940 & 9.369 & 0.076 \\
\hline
\end{tabular}

comparing the incidence of complications in patients receiving WF whether the WF was discontinued or not. Because dental extraction without WF cessation has become a standard procedure in patients receiving $\mathrm{WF}$, we conducted the present study to evaluate incidences of postextraction bleeding in comparison with patients who are not receiving anticoagulation therapy.

The present study is a nation-wide, multi-institutional prospective study that evaluated frequency of clinically significant postextraction bleeding and its difference between non-WF and WF groups. Clinically significant postextraction bleeding occurred at low rates in both study groups. Nonetheless, the difference between the two groups was $3.24 \%$; $95 \%$ CI $1.58 \%$ to $4.90 \%$.

Among the patients receiving WF, older patients showed lower risks for postextraction bleeding in the present study. Few studies have addressed influence of patients' age on incidence of postextraction bleeding. Mean PT-INR in the patients who experienced clinically significant postextraction bleeding was $2.57 \pm 0.62$ in patients 65 years of age or older, which was significantly higher compared with that in patients younger than 65 years of age $(2.10 \pm 0.39, \mathrm{p}=0.048)$. These results suggest that younger patients tend to experience clinically significant postextraction bleeding at lower PT-INR, which might have contributed to the lower bleeding risks in the elderly patients in the present study.
Few studies reported to date examined the relationship between age and the incidence of postextraction bleeding. Our finding indicated that extra caution should be taken when conducting exodontia in elderly patients receiving WF therapy, and the frequency of such situations would increase with ageing population.

A study that investigated the impact of comorbid conditions on haemostasis suggested that patients with liver dysfunction are another group at high risk for postextraction bleeding. ${ }^{22}$ The present study did not identify liver dysfunction or other comorbid conditions that would affect haemostasis as risk factors for increased incidence of postextraction bleeding. The attribution of such condition may have been underestimated in the present study as only $4.2 \%$ of the study participants had chronic hepatitis.

Our results also showed that the incidence of postextraction bleeding events increased with higher PT-INR, even though the values did not exceed 3.0. This finding suggests that special attention would be needed in patients whose PT-INR are close to 3.0 or higher to prevent postextraction haemorrhagic events. As WF sensitivity may vary among individuals and different ethnic groups, further studies will be needed to verify if the current findings are generalisable to other ethnic groups.

No randomised comparative trials that addressed incidences of postextraction bleeding in patients receiving WF with or without antiplatelet medicine have so far 
been reported. An observational study by Morimoto et al found no significant difference in incidences of postextraction bleeding between patients receiving WF alone and those receiving it in combination with an antiplatelet medicine. ${ }^{6}$ In contrast, Scully and Wolff ${ }^{23}$ reported that, in patients with oral surgeries, postoperative bleeding incidence was higher in patients under the combination therapy of WF and an antiplatelet medicine. Besides reports regarding the bleeding events associated with oral surgeries, increased incidence of haemorrhagic complications in patients receiving antiplatelet medicine in addition to $\mathrm{WF}$ compared with those receiving $\mathrm{WF}$ only was observed in a cohort study in Japanese patients under anticoagulation therapies. ${ }^{24}$ The results from the present study suggested that incidence for postextraction bleeding is lower in patients receiving WF along with an antiplatelet medicine. Although findings vary between studies, antiplatelet medicine alone is in general considered to minimally affect incidences of postoperative bleeding in cases of dental extraction ${ }^{8}$ or surgeries, ${ }^{25}$ and may as well in patients under the control of WF.

Suturing of wound and filling of the socket with oxidised cellulose or gelfoam have been widely recognised as efficient means of haemostasis after dental extraction. $^{26-28}$ However, some guidelines do not necessarily recommend suture of the wound, while supporting the use of oxidised cellulose, gelfoam or fibrin glue. ${ }^{8}$ Several reports also found that suturing could, rather, damage the tissue at the socket. ${ }^{29}{ }^{30}$ In the present study, incidences of postextraction bleeding in patients not receiving WF were not significantly different between the patients whose wounds were sutured and those without sutures $(0.6 \%$ and $0.2 \%$, respectively). However, we were unable to tell whether suturing increased the incidence of postextraction bleeding in the patients receiving $\mathrm{WF}$ as wounds were sutured in all the patients receiving $\mathrm{WF}$ in the present study. Evaluation of the outcome of suturing in patients receiving WF would be worthy of future study. Heparin bridging is another effective means to prevent thromboembolism and to reduce risk of postoperative bleeding, ${ }^{31} 32$ the application of which is primarily limited to a major surgery where topical haemostasis is not applicable. Efficacy of heparin bridging was evaluated by a randomised comparative study, ${ }^{33}$ which found no significant differences in incidences of postextraction bleeding or thromboembolic complications with and without addition of heparin bridging with continuing WF therapy, concluding that heparin bridging is not required when dental extraction is performed as long as topical haemostasis is applicable. On the other hand, comparative studies that examined cases of minor surgeries performed with cessation of WF with or without additional heparin bridging reported severe haemorrhagic events in cases receiving heparin bridging, though no thromboembolic complication had occurred. ${ }^{34}{ }^{35}$ Furthermore, heparin needs to be continuously administered intravenously when performing heparin bridging, necessitating hospital admission with resulting higher cost and demands for medical personnel. The results from the present study further supported the notion that topical haemostasis provides sufficient haemostasis in cases of simple tooth extraction without discontinuing $\mathrm{WF}$, and therefore heparin bridging is not necessary. Several aspects of our study design that may have affected the outcome of the present study should be noted. First, we included PT-INR values measured within 7 days prior to tooth extraction, considering the availability of measurement results. However, because effects of WF can be affected by diet and by other drugs, experts suggested measuring PT-INR within $24^{8} 93637$ and $48 \mathrm{~h}^{38}$ before the procedure. The British Committee for Standards in Hematology recommended $72 \mathrm{~h}$ before surgery. ${ }^{11}$ Therefore, the pre-extraction PT-INR values we utilised may not have accurately reflected the coagulation status immediately prior to the extraction, skewing the results of our analyses. To minimise the bias, we conduced another PT-INR measurement in patients receiving WF who experienced clinically significant bleeding events soon after the event observation. In such patients, PT-INR values before and after the tooth extraction were 2.27 and 2.26 , respectively, and not significantly changed. These data suggest that the possible bias derived from PT-INR values measured within 7 days in advance were minimal. Second, we performed all the analyses by tooth, not by patients. We hypothesised, based on previous studies that found no significant correlation between the numbers of teeth extracted and incidence of postextraction bleeding, ${ }^{2} 457$ that risks for postextraction bleeding may vary depending on the position and/or condition of the tooth extracted even in the same individual. In order to detect possible influences of local factors, such as position of tooth extracted (foretooth vs molar tooth) and gum conditions (presence of inflammation and/or inappropriate granulation) on risks for postextraction bleeding, we chose to present our data by tooth, despite a possible bias of including some of the patient data multiple times when multiple teeth were extracted from a single patient. When analysed by patient, clinically significant postextraction bleeding occurred in $2.77 \%$ and $0.39 \%$ in the WF and non-WF group, respectively, the difference between which was $2.38 \%(95 \%$ CI $0.65 \%$ to $4.10 \%$ ) and similar to that found in analysis by tooth. These data suggest that the bias that might arise from the analyses by tooth was minimal. Third, evaluation of the postextraction bleeding events was not blinded and choice of secondary haemostasis means were left at the discretion of the operator in charge, which might have affected the outcome of our analyses. However, the definition of the clinically significant bleeding events was made clear, minimising the influence by the person who evaluated the individual event. Indeed, there was little difference in postextraction bleeding incidence between patients whose wounds were sutured and those whose were not $(0.6 \$ \%$ and $0.2 \%$, respectively), further supporting the notion that means of haemostasis have minimally affected the present findings. 


\section{CONCLUSION}

The difference in incidence rates of postextraction bleeding between WF and non-WF groups was $3.24 \%$ (95\% CI 1.49 to $4.99 \%)$. Age, PT-INR and history of acute inflammation at extraction site were risk factors for postextraction bleeding in WF-receiving patients.

\section{Author affiliations}

${ }^{1}$ Department of Oral and Maxillofacial Surgery, Kanagawa Dental University, Yokosuka, Kanagawa, Japan

${ }^{2}$ Department of Oral \& Maxillofacial Surgery, Dokkyo Medical University School of Medicine, Shimotsuga-gun, Tochigi, Japan

${ }^{3}$ Department of Dentistry and Implant Center, Sanno Hospital, Minato-ku, Tokyo, Japan

${ }^{4}$ Nippon Dental University, Chiyoda-ku, Tokyo, Japan

${ }^{5}$ Tokyo Dental College, Chiyoda-ku, Tokyo, Japan

${ }^{6}$ Tokyo Women's Medical University, Shinjuku-ku, Tokyo, Japan

${ }^{7}$ Oral \& Dental Center, Aizawa Hospital, Matsumoto, Nagano, Japan

${ }^{8}$ Department of Dentistry and Oral Surgery, Ishikawa Prefectural Central Hospital, Kanazawa, Ishikawa, Japan

${ }^{9}$ Department of Epidemiology, National Institute of Public Health of Japan, Wako, Saitama, Japan

Contributors Hiroshi Iwabuchi designed the study protocol and wrote the manuscript. Hirohisa Imai analysed the data and contributed to edition of the manuscript. Hiroshi Iwabuchi, YI, SA, MS, G-yY, HO, KK and MM contributed to data collection. HN participated in data analyses. YI is the principle investigator of the present study. All the authors have approved the final version of the manuscript to be published.

Funding This research received no specific grant from any funding agency in the public, commercial or not-for-profit sectors.

Competing interests None.

Ethics approval The Ethics Committee of the National Hospital Organization Tochigi Medical Center, Tochigi, Japan.

Provenance and peer review Not commissioned; externally peer reviewed.

Data sharing statement Extra data can be accessed via the Dryad data repository at http://datadryad.org/ with the doi:10.5061/dryad.sg83p.

Open Access This is an Open Access article distributed in accordance with the Creative Commons Attribution Non Commercial (CC BY-NC 4.0) license, which permits others to distribute, remix, adapt, build upon this work noncommercially, and license their derivative works on different terms, provided the original work is properly cited and the use is non-commercial. See: http:// creativecommons.org/licenses/by-nc/4.0/

\section{REFERENCES}

1. Wahl MJ. Dental surgery in anticoagulated patients. Arch Intern Med 1998;158:1610-16.

2. Garcia DA, Regan S, Henault LE, et al. Risk of thromboembolism with short-term interruption of WF therapy. Arch Intern Med 2008;168:63-9.

3. Ogiuchi $\mathrm{H}$, Ando $\mathrm{T}$, Tanaka $\mathrm{M}$, et al. Clinical reports on dental extraction from patients undergoing oral anticoagulant therapy. Bull Tokyo Dent Coll 1985;26:205-12.

4. Evans IL, Sayers MS, Gibbons AJ, et al. Can WF be continued during dental extraction? Results of a randomized controlled trial. Br J Oral Maxillofac Surg 2002;40:248-52.

5. Sacco R, Sacco M, Carpenedo M, et al. Oral surgery in patients on oral anticoagulant therapy: a randomized comparison of different intensity targets. Oral Surg Oral Med Oral Pathol Oral Radiol Endod 2007;104:e18-21.

6. Al-Mubarak S, Al-Ali N, Rass MA, et al. Evaluation of dental extractions, suturing and INR on postoperative bleeding of patients maintained on oral anticoagulant therapy. Br Dent J 2007:203:1-5

7. Campbell JH, Alvarado F, Murray RA. Anticoagulation and minor oral surgery: should the anticoagulation regiment be altered? J Oral Maxillofac Surg 2000;58:131-5.
8. Morimoto $\mathrm{Y}$, Niwa $\mathrm{H}$, Minematsu K. Hemostatic management of tooth extractions in patients on oral antithrombotic therapy. J Oral Maxillofac Surg 2008;66:51-7.

9. Barrero MV, Knezevic M, Martin MT, et al. Oral surgery in the patients undergoing oral anticoagulant therapy. Med oral 2002;7:63-70.

10. Aframian DJ, Lalla RV, Peterson DE. Management of dental patients taking common hemostasis-altering medications. Oral Surg Oral Med Oral Pathol Oral Radiol Endod 2007;103(Suppl 1): S45e1-11.

11. Goodchild JH, Donaldson M. An evidence-based dentistry challenge: treating patients on WF (Coumadin). Dent Implantol Update 2009;20:1-8.

12. Nematullah A, Alabousi $A$, Blanas $N$, et al. Dental surgery for patients on anticoagulant therapy with WF: a systematic review and meta-analysis. J Can Dent Assoc 2009;75:41.

13. Perry DJ, Noakes TJC, Helliwell PS. Guidelines for the management of patients on oral anticoagulants requiring dental surgery. $\mathrm{Br}$ Dent $J$ 2007;203:389-93.

14. Sasanuki H, Aosaki M, Ikeda $\mathrm{Y}$, et al. Guidelines for management of anticoagulant and antiplatelet therapy in cardiovascular disease. Circ J. 2004;68(Suppl IV):1153-219.

15. JCS Joint Warking Group. Guidelines for pharmacotherapy of atrial fibrillation (JCS 2008): digest version. Circ J 2010;74 2479-500.

16. Japanese Society of Dentistry for Medically Compromised Patient, Japanese Society of Oral and Maxillofacial Surgeons, Japanese Society of Gerodontology: the Guidelines for Patients on Antithrombotic Therapy Requiring Dental Extraction. 2010 version Gakujutsusha Corporation Tokyo, 2010.

17. Balevi B. Should WF be discontinued before a dental extraction? A decision-tree analysis. Oral Surg Oral Med Oral Pathol Oral Radiol Endod 2010;110:691-7.

18. Balevi B. Should WF be discontinued before a dental extraction? Oral Surg Oral Med Oral Pathol Oral Radiol Endod 2012; 113:150-2.

19. Gaspar R, Brenner B, Ardekian L, et al. Use of tranexamic acid mouthwash to prevent postoperative bleeding in oral surgery patients on oral anticoagulant medication. Quintessence Int 1997;28:375-9.

20. Blinder D, Manor Y, Martinowitz U, et al. Dental extractions in patients maintained on oral anticoagulant therapy: comparison of INR value with occurrence of postoperative bleeding. Int J Oral Maxillofac Surg 2001;30:518-21.

21. Karsli ED, Erdogan O, Esen E, et al. Comparison of the effects of WF and heparin on bleeding caused by dental extraction: a clinical study. J Oral Maxillfac Surg 2011;69:2500-7.

22. Devani $P$, Lavery KM, Howell CJT. Dental extractions in patients on WF: is alternation of anticoagulant regime necessary? $\mathrm{Br} \mathrm{J} \mathrm{Oral}$ Maxillofac Surg 1998;36:107-11.

23. Scully C, Wolff A. Oral surgery in patients on anticoagulant therapy. Oral Surg Oral Med Oral Pathol Oral Radiol Endod 2002; 94:57-64.

24. Toyoda K, Yasaka M, Iwade K, et al. Dual antithrombotic therapy increases severe bleeding events in patients with stroke and cardiovascular disease: a prospective, multicenter, observational study. Stroke 2008;39:1740-5.

25. Maulaz AB, Bezerra DC, Michel $\mathrm{P}$, et al. Effect of discontinuing aspirin therapy on the risk of brain ischemic stroke. Arch Neurol 2005;62:1217-20

26. Halfpenny W, Fraser JS, Adlam DM. Comparison of 2 hemostatic agents for the prevention of postextraction hemorrhage in patients on anticoagulants. Oral Surg Oral Med Oral Pathol Oral Radiol Endod 2001:92:257-9.

27. Carter G, Goss A, Lloyd J, et al. Tranexamic acid mouthwash versus autologous fibrin glue in patients taking WF undergoing dental extractions: a randomized prospective clinical study. J Oral Maxillofac Surg 2003;61:1432-5

28. Blinder $D$, Manor $Y$, Martinowitz $U$, et al. Dental extraction in patients maintained on continued oral anticoagulant. Comparison of local hemostatic modalities. Oral Surg Oral Med Oral Pathol Oral Radiol Endod 1999:88:137-40.

29. Salam S, Yusuf H, Milosevic A. Bleeding after dental extractions in patients taking WF. Br J Oral Maxillofac Surg 2007;45:463-6.

30. Al-Belasy FA, Amer MZ. Hemostatic effect of n-butyl-2-cyanoacrylate (histoacryl) glue in WF-treated patients undergoing oral surgery. J Oral Maxillofac Surg 2003;61:1405-9.

31. Dunn AS, Turpie AG. Perioperative management of patients receiving oral anticoagulants: a systemic review. Arch Intern Med 2003;163:901-8. 
32. Kovacs MJ, Kearon C, Rodger M, et al. Single-arm study of bridging therapy with low-molecular-weight heparin for patients at risk of arterial embolism who require temporary interruption of WF. Circulation 2004:110:1658-63.

33. Bajkin BV, Popovic SL, Selakovic SDJ. Randomized prospective trial comparing bridging therapy using low-molecular-weight heparin with maintenance of oral anticoagulation during extraction of teeth. J Oral Maxillofac Surg 2009;67:990-5.

34. Garcia DA, Regan S, Henault LE, et al. Risk of thromboembolism with short-term interruption of WF therapy. Arch Intern Med2008;168:63-9.
35. Bloomer CR. Excessive hemorrhage after dental extractions using low-molecular- weight heparin (Lovenox) anticoagulation therapy. J Oral Maxillofac Surg 2004;62:101-3.

36. Chugani V. Management of dental patients on WF therapy in a primary care setting. Dent Update 2004;31:379-84.

37. Pototski M, Amenabar JM. Dental management of patients receiving anticoagulation or antiplatelet treatment. J Oral Sci 2007;49:253-8.

38. Brennan MT, Hong C, Furney SL, et al. Utility of an international normalized ratio testing device in a hospital-based dental practice. J Am Dent Assoc 2008;139:697-703. 